\title{
Rito, Tecnologia e Novas Mediaçōes na cena contemporânea brasileira
}

\author{
Renato Cohen
}

\begin{abstract}
Mantra Cosmico, Rede de presenças, a conectividade da net cria uma corrente de consciências, de sonoridades, de narrativas que são tecidas a distância. No espaço-tempo geodésico das 12 horas às 24 horas (horário SP) uma rede se constela criando uma geografia de 35 artistas e quatro cidades em link: São Paulo, Columbus (Ohio), Plymouth (UK) e Brasilia. $O$ Conceito é o do tempo real, do tempo epifánico e único. $O$ espaço está aberto para a performance presencial e telemática. Espaço aberto para os interatores da rede e para os livre depoimentos. Uma açäo que tem seu peso na materialidade do corpo e sua leveza no deslocamento das imagens ... (texto guia do evento Constela̧̧ão, 2002).
\end{abstract}

\section{Passagens da cena contemporânea crasileira}

produção cênica contemporânea no Brasil, incluindo-se as expressóes da performance, das artes visuais, do teatro e das recentes categorizaçōes de Arte e'Tecnologia, demarca um constante dialogismo entre o uso de novos suportes - com a apropriação das redes telemáticas - e os ritos ancestrais e a etno- cultura, operando os conceitos de "antropofagia" e tribalismo nos contextos dos anos 90 .

Artistas como os videoastas Artur Omar e Sandra Kogut perfilam imagens de devoração pela selva amazônica, nas extensóes do corponatureza, Gilbertto Prado, em seu experimento de realidade virtual Deserdesejo (2001), evoca espaços xamânicos de interação, a performer Maura Baiocchi cria uma web-shaman, fumando longos charutos dedicados à Ogum e as entidades afro-brasileiras diante das imagens virtuais do mar da Bahia. Nos trabalhos de minha autoria, como criador e encenador, particularmente as montagens de $K a$ (1998), de Vélimir Khlébnikov, Ueinzz-Viagem à Babel (1997) e o recente evento Constelação (2002), tenho trabalhado com xamanismo e o corpo em transe, com uma figuração de um "corpo antropolólogico" nas mediaçóes com a loucura, e na busca de novas replicaçóes da imagem e da presença que vão do uso de cenários virtuais - tridimensionais - aos trabalhos em redes telemáticas, com entrada de dados ao vivo.

Numa cartografia da criação contemporânea brasileira, são relevantes, portanto, os deslocamentos espaciais, incorporando territórios

Renato Cohen (1957-2003) foi professor do Programa de Comunicação e Semiótica da PUC-SP e do Departamento. de Teatro da Unicamp. Dirigiu o grupo Mídia Ka, de Performance e Tecnologia. Publicou os livros Performance como Linguagem (Perspectiva, 1987/2003) e Work in Progress na Cena Contemporânea (Perspectiva, 1998). Este artigo foi apresentado no Congresso de Hispanistas alemães, realizado em Berlim, em junho de 2003. 
mitologizados, como nos trabalhos de Antonio Araújo, nos espaços de igrejas e penitenciárias, as novas apropriaçóes do corpo no espaço, com artistas como Laura Lima e Tunga que retomam a linhagem conceitual proposta por Ligia Clark e Hélio Oiticica com os conceitos de corpo-bicho e o uso de parangolés, vestíveis; e todas as mediaçóes com tecnologia, desde as experiências de Eduardo Kac, que implanta chips em seu corpo até as disjunçôes de Lucas Bambozzi, Eder Santos e outros artistas visuais que cosntelam disjunções de corpo, voz, espaço aos espaços contelados e ritualizados das redes.

Essa nova experimentação estética e corporal, que a meu ver, instaura um campo de ampliação do espectro çênico e proporciona um transbordamento dos gêneros e das linguagens, tem como linhagem comum a performação ao vivo, e é, politicamente, acompanhada também pela incursão de novos sujeitos à cena, legitimados por novos olhares, incluindo-se a presença de atores loucos, índios guarani, trabalhadores sem-terra e uma nova gama de não atores com incursóes e novos agenciamentos que o filósofo Peter Pelbárt nomeou como novo capital biopolítico de interlocução. Outros artistas, da novíssima geração, tem se articulado em coletivos e em açōes de mídiaativismo podendo ser citados, entre outros, o grupo Corpos Informáticos, de palavra feminista e o recente $A$ Revolução não será Televisionada.

Essas novas operações cênicas, transmutam o espaço do teatro e do drama institucionalizado a ponto do recente evento "Próximo Ato de Teatro Contemporâneo" - do ItauCultural, em que participei, abrir uma mesa de discussão intitulada Pós-Teatro.

Pretendemos, nessa linha, apontar novas figurações do corpo que acompanham esses agenciamentos cênicos incluindo as categorias do corpo extenso (corpo estendido nas redes), do corpo híbrido, estudando as passagens das mediaçóes primárias - rituais - às tecnológicas com os aportes da vídeo-arte, da net e da webarte no estudo dos novos processos de transmediação, com o uso de hipertextos e hipermídias nos agenciamentos do corpo, narrativa e recepção - interação com a obra em progresso.

Nessa ordem, serão examinados dois processos criativos distintos, em particular o trabalho com o Grupo Ueinzz - formado por atores esquizofrênicos e portadores de outras desordens psíquicas e modos distintos de subjetivação e organização de mundo, interessando, nesse caso, a mediaçáo com a alteridade - e o evento Constelação (ver www. sescsp.org.br/sescl hotsites/constelacao/constelacao.htm), sob minha curadoria, performance telemática, que reuniu quatro centros internacionais de irradiação de imagens e se estendeu por 12 horas, constelando 25 artistas distintos, operando em tempo real e em interiscrituras coletivas de texto e imagem. A meu ver, tais trabalhos distintos, tem em comum o traço do contemporâneo, quer seja o lidar com o acontecimento e não com a representação - seja pela força da loucura, disruptora, num caso, e pela extensão do "tempo real", no outro, ativando outras relaçóes de espaçotempo e recepção (a platéia é composta de interatores) e com uma organização narrativa que é permeada por intertextos organizando-se na órbita do hipertexto, como rede de agenciamentos e subjetivaçóes de diversos sujeitos.

\section{Corpo e Alteridade: Viagem à Babel como experiência de outramento}

A Cia. Ueinzz, formada por atores usuários dos Serviços de Saúde Mental do Hospital Dia a Casa, com seus cinco anos de existência e três espetáculos maiores realizados: Ueinzz-Viagem à Babel (1996-7), Dédalus (1997-2000), inspirado nos mitos do labirinto e Gothan Sp (2002), intertexto das Cidades Invisíveis de Calvino e de São Paulo, como Gotham, corrobora com seu percurso a fundação de um território cênico, o "teatro do inconsciente"

Na trilha do imaginário em cena, já proposto pelos surrealistas, resgatando a protocena Dadá, o teatro da crueldade de Artaud, e as inúmeras experiências limiares do happening, da 
performance e do teatro contemporâneo - o trabalho de Bob Wilson com o autista Christopher Knowles -, a "cena da loucura", dos corpos atravessados por forças e encadeamentos desconcertantes, das subjetividades limítrofes, instaura um novo topos cênico, de potência, de verdade, de pára-representação. O primeiro espetáculo da Cia. Ueinzz, foi apresentado em 1997 nos teatros Tuca Arena e Oficina, em São Paulo. O nome da Cia. foi tirado de um paciente que balbuciava - "eu...uein...uein... zzz..", sons glossolálicos, que se transformaram na palavra "Ueinzz", que alguns liam como figura de tempo (when) e o zzzzzzz, do sono.

Como roteiro, uma trupe nômade, saída das Trevas do primevo Caos do Universo, perambulava no deserto numa longa e ziguezagueante travessia, em busca da luminosa Torre de Babelina. Ao consultar um oráculo, a trupe ouvia a palavra mágica Ueinzz. Este som, que ressoa como um enigma através dos tempos, tem o poder de despertar os andarilhos da Terra e dar sentido à sua deriva. Guiados por um profeta e visionário, podem enfrentar a Tempestade, a Esfinge e o Imperador Anarquista, vislumbrando ao longe, como uma miragem promissora, a lendária Torre.

A especificidade dos atores, usuários de serviço de saúde mental, coloca a ação em sua dimensão trágica original, relacionando os mitos pessoais e as histórias universais, em um novo dialogo entre atores e personagens. A cena acontece entre a epifania e a ausência, entre o acontecimento e perda.

As relaçōes entre atuantes e platéia, entre a gênese poética e sua performance, entre o texto e sua presentação estão alteradas por esses novos sujeitos da cena: corpos que ganham outro alinhamento, consciências que criam outro tempo cênico, um tempo da espera, do imprevisto, do espontâneo, construçóes cênicas que propóem a suspensão e a materialidade, mecanismos esses que afirmam uma cena - emblemática do contemporâneo - sustentada no acontecimento e não na representação.
Do ponto de vista dramatúrgico, os atores-performers da Cia Ueinzz compóem um intertexto entre seus próprios textos internos e as poéticas de contorno propostas pela direção. São lançados alguns textos e situaçōes criativas no processo de criação, como por exemplo, em Dedalus, "desenhe seu labirinto", ou "pegue essa mala" (que é colocada como objeto), "faça sua viagem, vá a algum lugar" - situaçōes inaugurais que propóem a viagem, o deslocamento, o nomadismo. Como resposta, recebemos as lógicas paradoxais: "o labirinto anda", "com essa mala eu não vou a lugar nenhum". O texto do espetáculo vai sendo tramado a partir dessas pequenas histórias, de uma lógica que projeta a curva, o inesperado e não a reta cartesiana. De um plano onde emergem densidades, pesos, gravidades próprias da experiência humana, em condensaçōes, deslocamentos e outros mecanismos sincrônicos com as elaboraçóes do inconsciente, que neste caso está a flor da pele.

Essa dramaturgia de palavras, espasmos, movimentos, vai sendo tecida entre a direção, os atores e intuiçóes que dialogam com o entorno contemporâneo ao longo da criação do espetáculo, que se configura como um work in progress. Com textos de contorno são acionados mitos e poéticas inaugurais, como o mito do labirinto, o mito da travessia, os percursos do herói, fragmentos de Hesíodo, Paulo Leminski, ftalo Calvino e outros poetas, textos esses que ganham deriva e disjunção na medida em que são rearticulados pelos atores. A voz dos atores, mediados por seus inconscientes ativos, é que forma então a língua, a língua do espetáculo. $\mathrm{O}$ ator que produz o som ueinzz, tem esse som amplificado. Seu som é uma glossolalia, um mantra que ganha sentido profético, que guia toda a companhia em seu trajeto cênico.

Aos diretores-dramaturgos cabe a tarefa hermenêutica de trabalhar toda a intertextualidade, dando conjunto cênico aos textos cifrados, dobrados, que vão se apresentando, sugerindo textos da cultura que dialoguem com os pequenos mitos enunciados, formando um caldeirão textual que acolha as diferentes ca- 
madas dessa "cultura das bordas", que aqui vai se formando.

O espetáculo se forma enquanto acontecimento, e na presença do público os atores desenham a partitura que vem sendo tramada e ensaiada ao longo do processo. São organizados sketches fixos e uma marcação espacial que prevêem o improviso e o achado cênico. Os atores singulares, guiados pelo espaço e por uma partitura musical que se desenrola ao vivo, criam seu próprio desenho cênico. O espetáculo conforma marcação e espontaneidade, identidade cênica e distanciamento, aproximaçăo do personagem e presentaçáo do eu próprio em cena. Atores que largam sua posição para assistir a cena dos outros, e retomam na seqüência dramática. Atores que realizam grandes monólogos e, também, que abandonam a cena sem completar suas frases. Essa estridente partitura de erros, de achados, de reinvenção do texto, vai se construindo na frente do público que está convocado como cúmplice desse novo entoar da "língua mágica". O espetáculo se torna então ritual, onde todos assistem o impossível prosseguir, aos corpos dobrados dançarem, as vozes inaudíveis ganharem potências amplificadas pela eletrônica montada no espetáculo..

Os atores da Cia. tem a seu favor um raro aliado, que desmonta a representação, no seu sentido mais artificial: o tempo. $O$ tempo do ator incomum é mediado por todos seus diálogos, é transbordado por seus sub-textos, que passam a ser o próprio texto. A resposta nos diálogos não vem imediata, racional, ela percorre outras circuitaçooes mentais. Há um delay, um atraso cênico, que coloca toda a platéia em produção. $\mathrm{O}$ ator, intuitivamente, transita entre a identificação stanislavskiana e o distanciamento de Brecht. E se empolga, perante o aplauso do público, realiza sua tourada cênica, medindo forças com a platéia e suas próprias sombras interiores.

Os singulares atores da Cia. propõem, a nosso ver, um estatuto inaugural de articulação de texto e de corpo no espaço, um estranho diálogo entre vontade de ação e outras forças que vão apresentar um contra desenho, uma performance limite, cujo gesto se delineia entre opostos: fragilidade e potência, em um traço contínuo de ambigüidade e ambivalência.

\section{Corpo Estendido nas Redes: Passagens do Moderno para o Contemporâneo}

A criação de novas arenas de representação com a entrada, onipresente, do duplo virtual das redes telemáticas (WEB-Internet), amplifica o espectro da performação e da investigação cênica com novas circuitaçōes, navegação de presenças e consciências na rede e criação de interiscrituras e textos colaborativos. Com uma imersão em novos paradigmas de simulaçáo e conectividade, em detrimento da representação, a nova cena das redes, dos lofts, dos espaços conectados, desconstroi os axiomas da linguagem teatro: atuante, texto, público - ao vivo, num único espaço, instaurando o campo do Pós-Teatro.

A recém nomeada tecnocultura $e$ as navegaçōes pelo universo "cyber" (Gibson) -das redes virtuais - colocam o interator contemporâneo em novas relaçóes de espaço, tempo, presença, memória. Estão em causa as estruturas hipertextuais, a comunicação em telepresença, os ambientes multiusuários e a possibilidade de audiências refratadas no tempo e no espaço.

Navegando em suportes hipermídia, por ambientes imersivos, os interatores contemporâneos recuperam a idéia de "tempo real" em contraposição ao tempo simbólico do espetáculo. Os novos dispositivos promovem outros agenciamentos de simulação, de interação, de comunicação on-line com o evento, em descontrução aos modelos cênicos da representação.

As redes da Internet - na nova revoluçáo telemática - dão voz e interatividade aos interatores que passam a ser sujeitos de uma cena multiplicada, polifônica, e não meros receptores distanciados. $\mathrm{O}$ mundo sensorializado estende nossa pele e nossa consciência a todos os es- 
paços do rede tecendo os nós da "noosfera" e dos novos meios comunicantes.

A relação axiomática da cena: corpo-texto-audiência, enquanto rito, totalização, implicando interaçóes ao vivo é deslocada para eventos intermediáticos onde a telepresença (on line) espacializa a recepção. $O$ suporte redimensiona a presença, o texto alça-se a hipertexto, a audiência alcança a dimensão da globalidade. Instaura-se o topos da cena expandida: a cena das vertigens, das simultaneidades, dos paradoxos na avolumação do uso do suporte e da mediação nas intervençóes com o real. Gera-se o real mediatizado, elevado ao paroxismo pelas novas tecnologias onde suportes telemáticos, redes de ambientes WEB (Internet), CD-ROMs e hologramias que simulam outras relaçōes de presença, imagem, virtualidade.

$\mathrm{Na}$ linha conceitual proposta por Rosalind Krauss (Escultura em Campo Ampliado) a cena Pós-Teatral é a cena ampliada, onde as cidade, as redes, os espaços comunicantes são o cenário do trauerspiel contemporâneo. Uma cena que altera as noções de presença, corpo, espaço, tempo, textualidade, pela inserção da simultaneidade, da velocidade e que - ao mesmo tempo é plena de dramaticidade ao figurar o acontecimento, o evenément, em escala social e subjetiva. Uma cena inclusiva, performática, que inclui inúmeras trocas entre cibernautas - em eventos de curadoria, como o evento Constelação (Sesc, 2002), curadoria Renato Cohen, rede que linkou, em tempo real, quatro centros de irradiação (Sesc-São Paulo, Caiia Center-UK, Ohio Media Center-Columbus, USA e Centro de Mídia-UNB), num período de 12 horas com sequiência de performances $\mathrm{e}$ interiscrituras - $\mathrm{e}$ eventos livres, autonômos, na produçáo micropolítica e desejante dos cibernautas - em chats, web-cam e páginas pessoais.
A contaminaçáo do teatro com as artes visuais, cinéticas e eletrônicas dá um novo salto com a emergência das redes telemáticas que permeiam uma comunicação em tempo real, e uma extensão do corpo e da presença (o corpo extenso) - que é eminentemente performatizada. A partir dos anos 90, os novos mídia tecnológicos (web-art, artetelemática, net-art), com novos recursos de mediação, virtualização e amplificação de presença, passaram a impor outras direçôes às experiências radicais da Performance e do Teatro: Johannes Birringer ${ }^{1}$ nomeia um novo espaço monádico de performaçáo - a sala tecnológica, recebendo imputs em tempo real em contraposição à sala instalação, remetida às Artes Plásticas. Como em sua criação Vespucci $(1999)^{2}$, performance com uso de espaço computacional, cantoras líricas e bailarinas, alimentadas em tempo real por informaçōes da Nasa e redes de CD-ROMs, onde o público recompóe todo o hipertexto da criação. Esses novos espaços de performação, intensamente alimentados por dados - em tempo real - colocam os performers e a audiência em espaços simulados de improviso e presentificação.

Essa extensão, do espaço cênico, no espaço virtual, não pressupõe, a nosso ver, uma "desrealização" das formas e presenças e sim uma reconfiguração de cena e comunicação à luz dos novos suportes e materializaçōes da Arte-Ciência contemporâneas. Esse projeto de "desrealização" da cena, na verdade, um ataque à cena naturalista, tem sua gênese no século $\mathrm{XX}$, com o projeto de um teatro não mimético - na cena bio-mecânica de Meierhold, na rota das surmarionetes de Gordon Craig, nas utopias futuristas de Khlébnikov, Shlemmer e El Lissitski, que intentam um corpo que atravesse os médiuns (Khlébnikov fala de uma linguagem mediúnica, o zaum, que atravesse os mídias).

1 Em BIRRINGER, Johannes. “Contemporary Performance/Technology”. In: Theatre Journal, 51, 36181, 1999.

2 Vespucci (Direção Johannes Birringer, 1999), Dalas, Usa, Alien Nation Co. 
Nesse projeto - antirealista - novas escrituras se desenham: Khlébnikov cria o $K A$ (1916) - um prenúncio de hipertexto que enumera o Egito de Amenóphis e as terras do homem do futuro. O suprematista Kasimir Malévitch e Maiacovsky, desenham ícones abstratos e palavras autônomas na criação de uma nova cena da poiesis. São fundantes, dessa gênese, o formalismo futurista, o sonorismo dadá, a fluxo automático dos surrealistas - $\mathrm{e}$ as experimentaçóes com a body-art, o conceitualismo, e o minimalismo que vão compor as matrizes da cena contemporânea

No projeto contemporâneo, uma cena pré-virtual se desenha nos experimentos da Arte-Performance em inúmeras intervençōes com tecnologia, juntando corpo, narrativa e pesquisa de suportes: os experimentos sonoros. $\mathrm{O}$ advento de novos suportes tecnológicos, com a presença das redes telemáticas (Web-Internet), dos extensores do corpo e da mente nos novos suportes digitais, promove outras relaçôes de presença, mediação e relaçáo com a escala dos fenômenos.

Certamente, as artes computacionas, com as redes, promovem uma mudança de paradigma na Arte e na Comunicação, preconizada no Moderno e materializada no Contemporâneo, colocando o usuário-interator "dentro" da cena, experienciando o processo em sua totalidade: como define Artur Matuck, o interator estará navegando ou circuitando um dispositivo criado por um Meta-Artista (Media Design), muitas vezes dispondo dos mesmos dados e parâmetros desse contrutor.

Essa totalização das Artes em códigos, visuais, sonoros, legíveis e táteis, tem sua gênese nas idéias da Gesamtkunstwerk (Obra de Arte Total), proposta por Richard Wagner, que propóe partitura e sincronia das artes, incorporando a cinética, a visualidade, os usos de simultaneidade, as arquiteturas do texto. A Arte Performance, desde a Modernidade tem sido, por natureza, a arte midiática, das revoluções de suporte, operadora dos trânsitos e passagens contemporâneas.
Nesse contexto contemporâneo, a "performação" (experimentaçáo) contrapõe-se aos paradigmas da representação: aos espaços "auráticos" da cena (edifícios-teatro, museus) contrapõe-se o espaço vivo das ruas, dos galpóes, dos domínios da rede (Web-Art). A recepção passiva da obra nomeia-se o interator. A conhecida equaçáo cênica texto-público-atuante, matriz do Teatro, interpóem-se, na performance contemporânea, uma cena descontínua, amplificada, operada em espaços-tempo simultâneos, com outros níveis de presencialidade: o grupo Corpos Informáticos, de Brasília, performa, ao vivo, em web-cams para platéias de outros países. Eduardo Kac (Time-Capsule) implanta chips em seu corpo - metáfora de memória, subjetividade e da sociedade de controle.

Fabian Wagminster, no encontro Repercute-Reflexiones sobre Performance, Cultura $y$ Tecnologia, recentemente realizado em Los Angeles, em que participamos (ver digitalcultures. isop.ucla.edu/repercute/transparency.gif) aponta a similaridade entre a Arte Telemática ( $D i$ gital Art) e a Arte Performance, pela efemeridade dos eventos, pelo aporte da arte conceitual e de campos de imanência, pelo seu caráter imaterial, desenhando rastros, cartografias de processo em seus agenciamentos.

$\mathrm{O}$ aporte das novas tecnologias que amplificam os mecanismos de mediação, virtualização e refratação da percepção, e captação de códigos sensíveis que demarcam tempos, espaços, corporiedades, vão legitimar uma série de experimentos, eventos - da ordem de uma cultura das bordas - que passam a se inscrever no campo da cultura. A questão que se propõe na arte da performance é de uma mediaçáo e intervenção nos planos de realidade, superando os limites entre os campos do real e da ficcionalidade, entre sujeito e receptor da obra, dando complexidade e polissemia à produção do evento, que passa a ser culturalizado.

Esses novos espaços dramáticos, advindos da performance e conquistados na Modernidade, na égide do relativismo, de uma nova estética das intensidades, do ultra-realismo, operam 
no trânsito das Artes, dos corpos-instalados, das palavras amplificadas, dos primeiros suportes eletro-acústicos. A performance instala-se como arte híbrida, ambígua, oscilando entre a plena materialidade dos corpos e a fugacidade dos conceitos.

Nessa direção, a performance contemporânea - mediada por novos suportes - reinstaura a capacidade mitificadora e a demanda por produção de novo sentidos que se somam a essas sintaxes vertiginosas. Há um retorno ao "tempo real", tempo da experiência, tempo do contato - mesmo que virtualizado - entre múltiplas possibilidades de subjetivação. Da mesma forma, a performance como arte sintática e de mediação, por natureza, cria operadores que articulam as novas relaçōes entre homem e seus extensores maquínicos, sejam eles avatares, corpos híbridos ou telepresenças.

As novas culturas tecnológicas, criadas por ambientes de interatores e produtores, com acessos as redes $\mathrm{e}$ as novas experiências de arte e comunicação, formam novos grupos sociais, onde vida e arte, cotidiano e virtualidade, leigos e artistas navegam os novos territórios da sociedade tecnológica.

Os novos suportes midiáticos vão propor outras linhas de investigaçáo à performance: trabalhando corpos, bases de dados, comunicaçōes, informaçōes à distância as operaçōes transitam de forma heurística sob o novo paradigma da simulação-interação. São construídos, maquínicamente, sistemas de simulação, que reinterpretam dados e situaçōes à distância. $\mathrm{O}$ paradigma da simulação, de certa forma, reitera o campo de representação, por trabalhar a referencialidade, porém opera o território da criação de realidades virtuais.

A partir dessas inferências podemos, preliminarmente, estabeler uma pequena tipologia de trabalhos, com tecnologia, onde se experenciam diversos níveis de interelação entre os campos da phisis (estudo do corpo e das aesthesis) e da teckné (estudo das técnicas, leis e tecnologias) nas redes telemáticas.
Corpos Estendidos: Na linha anunciada por McLuhan, extensores de corpos e sentidos estão presentes nas obras de artistas como Stelarc, e nos diversos trabalhos de telepresença. Operam a extensão de corpos à distância, para platéias segmentadas no tempo e no espaço. Proporcionam níveis de interação simulada. Trabalham o real simulado no virtual e devolvido ao real (por exemplo com um performer, em presença, na França, simulando seu corpo na rede e sendo apresentado, em tempo real, para platéia presencial no Brasil).

Corpos Hibridizados: Trabalhos diversos, como os do Fura del Baus, de Stelarc, de Eduardo Kac, entre outros, com instalação de sensores e aparatos no próprio corpo corroborando as interelaçóes modernistas do homem-máquina. Nesse grupo a tecnologia não opera como campo tele e sim como corpo híbrido. A interferência se dá no corpo do performer e, não, a partir desse corpo. Essa operação pode estar conectada a rede com sensores comunicantes ou náo.

Hipermídias: Prolongamento das pesquisas modernistas, de uso de máquinas e suportes eletrônicas, no campo digital, que opera outros níveis de memória e de criação de realidades visuais. As telas amplificadas de cristal líquidas, criam imagens que alcançam o estatuto da "hiperealidade", muitas vezes operando como cenários virtuais ou mundos imaginários projetados. Nessa ordem, incluem-se a maior parte dos trabalhos intertextuais e hipertextuais, criando redes de imagens-mundo, desde o cinema de Peter Greenaway até o recente trabalho do grupo teatral americano Wooster Group: Em Phedra (NovaYork, 2001) os performers tem suas coreografias e movimentos anunciados previamente em telas DVD, que projetam um devir-corporal, em paralelo ao espaço textual e cênico de sua performance.

Criação de Ambientes e Interferências: Performances que operam com sinais, índices, rastreamentos de campos e corpos sensorializados. Representam uma última geração de pesquisa, ao sair da representação icônica e, trabalhar, majoritariamente nas traduçôes indiciais. 
O grupo alemão Knowbotic Research realiza performances com entrada - on line - de sinais de tempo da estação alemã da Antártica, ou com sinais do trânsito de Tokio. Criam uma nova linhagem de performance que opera, em interação, com sinais ambientais, uma performance de environment. A americana Maída Whiters cria performances com sinais, ao vivo da Nasa, $\mathrm{da}$ aurora boreal em diversos pontos do sistema solar. Os brasileiros do Sci-Arts, realizaram performances transformando sinais de trabalhos apresentados em salas simultâneas.

Performances em Tempo Real: Trabalhos na linha de espetáculo, na categoria de arte telemática, usando usando redes em tempo real. Trabalhos como Vespucci, de Johannes Birringer, cujos performers recebem, a todo momento, pela rede, imputs sonoros e visuais da Nasa, ou o recente trabalho do encenador americano
Bob Wilson - Monsters of Grace, na linha nomeada do "Cyberstage" (www.cyberstage.org/ archive/newstuff/monsters.html). No Brasil, grupos como o Sci-Arts, trabalhos como os de Tânia Fraga, Diana Dominguez, das designers Rejane Cantoni, Daniela Kutchat e a performer Ivani Santana, produzem trabalhos de corpo sensorializado que operam em tempo real com o ambiente instalado proporcionando varreduras de imagens, sons e realidades mediadas (Ver Op-era, 2000).

Interiscrituras: Trabalhos com realização de dramas e textos - em autoria comparilhada na rede. Uma seqüência importante de trabalhos são os de hiperdrama (Michael Joyce) e construção compartilhada de textos na rede, com comunicaçáo interativa entre autor-obrainterator. No Brasil são relevantes as construçóes textuais de Artur Matuck, entre outros.

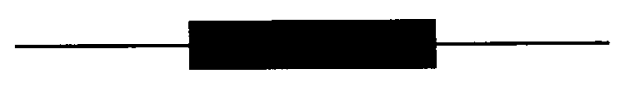

\section{Referências Bibliográficas}

BIRRINGER, Johannes. “Contemporary Performance/Technology”. In: Theatre Journal, 51, 36181, 1999.

Performance on the Edge: Transformations of Culture. Londres/New Brusnwick, AthloneContinuum, 2000.

CANTONI, Rejane. Realidade Virtual. Uma história da imersão interativa. Tese de Doutorado. PUCSP, 2001.

COHEN, Renato. Performance como Linguagem. São Paulo, Perspectiva, 1989.

. Work in Progress na Cena Contemporânea. São Paulo, Perspectiva, 1998.

DELEUZE, Gilles. Leibnitz et le Baroque. Paris, Minuit, 1988.

MEDEIROS, Maria Beatriz de. Arte e Tecnologia na Cultura Contemporànea. Brasília, Ed. da UNB, 2002.

PRADO, Gilbertto. "Experimentaçōes Artísticas em redes telemáticas e Web". In: LEÃO, Lucia (org.). Interlab-Labirintos do Pensamento Contemporaneo. São Paulo, Iluminuras, 2002. 